\title{
Analyzing Failed Institutional Change Attempts ${ }^{1}$
}

Sukriti Issar ${ }^{2}$ and Matthias Dilling ${ }^{3}$

${ }^{1}$ We would like to thank Ezequiel Gonzáles Ocantos, Emiliano Grossman, Inga Rademacher, Antonia Zimmermann, and three anonymous reviewers for their generous comments and feedback.

${ }^{2}$ Assistant Professor, Sciences Po, Observatoire Sociologique du Changement (OSC), CNRS, 98 rue de 1’Université, Paris 75007, France; +33 (0) 1454 95485; sukriti.issar@sciencespo.fr.

${ }^{3}$ Departmental Lecturer in Comparative Politics, University of Oxford; DPIR, Manor Road Building, Manor Road, Oxford, OX1 3UQ, UK; +44 (0) 1865278717 ; matthias.dilling@politics.ox.ac.uk. 
Theoretical advances in the study of institutional change center around a productive paradox. While change agents can take strategic action to change institutions, institutions display a remarkable level of formal stability. From this paradox, we expect that attempts to change institutions are an empirical regularity and that many formal change attempts will fail. This article contributes to historical institutionalism by analyzing the political effects of failed formal institutional change attempts on institutional sequences. Failed institutional change attempts could be mere blips, having little effect on subsequent institutional trajectories, or even inoculate against future attempts. Failed attempts could also lay the ideational groundwork, aid in coalition building, and garner concessions for subsequent institutional change, or convince change agents to alter their strategy. The article suggests analytical strategies to assess the effects of failed institutional change attempts, drawing on examples from comparative politics and two extended case illustrations from Italian party politics and the Affordable Care Act in the US.

Keywords: institutional change, failed attempts, negative cases 


\section{Introduction}

Theoretical advances in the study of institutional change center around a productive paradox about institutions and strategic action. Change agents can take strategic actions to set in motion processes of institutional change (e.g. Hacker 2004; Mahoney and Thelen 2010). These actions are, however, structured and constrained by the existing institutional framework (e.g. Gingrich 2015; Capoccia 2016). From these two perspectives, we can expect that attempts to change institutions are an empirical regularity and that many of these attempts will fail. This article contributes to the theoretical conversation on institutional change through an analysis of failed institutional change attempts and their effects on institutional sequences. The gradual institutional change literature has focused on cases where existing institutions have been changed incrementally or where the interpretation or enactment of existing institutions has changed due to changes in context (e.g. Waylen 2014; Mahoney and Thelen 2010; Streeck and Thelen 2005). These processes are often the result of the politics between change agents and supporters of the status quo. The tension between these two groups is also at the core of failed institutional change attempts. In this class of events, a proposal for institutional change reaches but does not succeed in passing a formal decision point. Failed institutional change attempts are a frequent occurrence in political institutions, and can be observed across issue domains and levels of analysis. They have characterized Europe's gradual development toward democracy (Ertman 2010; Ziblatt 2017), Japan's 1994 electoral reform (Reed and Thies 2003), the adoption of the EU's Treaty of Lisbon in 2007, and changes in party organization in 1960s Italy. Failed institutional change attempts also characterize ongoing institutional trajectories, including attempts to revoke Uruguay's controversial amnesty law (Zebley 2011), pass gender and equal opportunities 
legislation in Nigeria (Payton 2016), and repeal the Affordable Care Act in the US (Béland et al. 2020).

Although authors have empirically identified failed attempts in specific cases (e.g. Immergut 1992a; Tulis and Mellow 2018; Ziblatt 2017), the role of failed institutional change attempts in institutional sequences remains under-explored (with notable exceptions on near misses, Capoccia and Kelemen 2007; Capoccia and Ziblatt 2010). This paper contributes to the literature on historical institutionalism by formulating an analytical strategy to assess the political effects of failed institutional change attempts on the post-failure trajectory of an institution. Section I conceptualizes failed institutional change attempts and demarcates them from the related concepts of negative cases and near misses. Section II elaborates on strategies to analyze the connection between successive institutional change attempts and assess alternative explanations for how failed change attempts can influence subsequent institutional development. Section III demonstrates that failed institutional change attempts can lay the ideational groundwork, aid in coalition building, and garner concessions that change agents could build on in subsequent change attempts. Contending ideas could be introduced and linked to institutional alternatives, attracting new constituencies, pushing supporters of the institutional status quo to compromise, or providing the discursive arsenal for future change attempts (Case Illustration 1: attempts to introduce proportional representation in post-war Italy's dominant political party). Section IV shows that failed institutional change attempts could lead to no significant new ideas, coalitions or concessions and instead have different effects on the post-failure trajectory of an institution. Failed attempts could inoculate institutions against further attempts (e.g. if contenders show their hand too early or suffer a demoralizing defeat), or encourage change agents to switch strategies (Case Illustration 2: attempts to repeal the Affordable Care Act in the US in 2017). The case 
illustrations are not structured comparisons for each other and the focus is instead on with-in case analysis. The empirical examples highlight the suppleness and broad applicability of the analytical strategy proposed in this paper to assess the role that failed attempts can play in institutional trajectories. Section V concludes by discussing failed institutional change attempts as important drivers of institutional development.

\section{Failed Institutional Change Attempts, Negative Cases, and Near Misses}

The study of institutions has attracted much substantive interest in comparative politics in recent decades. Scholars have applied institutional theories to study constitutions and regimes (e.g. Bernhard 2015), political organizations (e.g. Hunter 2010), and policies (e.g. Pierson 1993). They typically build on North's (1990: 3) widely accepted definition of institutions as "the rules of the game in a society, $[\ldots]$ the humanly devised constraints that shape human interaction." Over the years, the conceptions of institutions and institutional change that researchers have in their toolkit have shifted. Earlier conceptions focused on the power of institutions to structure the behavior and preferences of social and political actors (Pierson 1993, 2000; Mahoney 2000). Institutions were thought to be relatively stable - both in their composition and their effects. This conception was very fruitful in driving research on path dependence, institutional stickiness, punctuated equilibrium, and the potential for lock-in of political choices. Methodologically, it led to an interest in identifying critical junctures and in analyzing episodes of formal institutional change (Capoccia and Kelemen 2007; Capoccia and Ziblatt 2010). In the past decade, the focus of researchers has shifted away from episodes of formal institutional change (i.e. the replacement of rules by new ones) toward a more plastic view of institutions that focuses on change agents 
and the practices by which institutions are enacted (Streeck and Thelen 2005; Mahoney and Thelen 2010). In this view, institutions "are fraught with tensions" over resources and power, which entail continuous political maneuvering "to resolve institutional ambiguities" (Mahoney and Thelen 2010, 8-9). As a result, institutional change emerges endogenously, gradually, and frequently, with the potential to culminate in major transformations (Streeck and Thelen 2005).

Recent research has sought to mediate between the sticky and plastic properties of institutions by asking how institutions become the site of strategic action while also constraining the scope of this action (Gingrich 2015; Capoccia 2016). Institutions affect the allocation of power between change agents and supporters of the status quo, thereby restraining the former's prospects of realizing institutional change. For example, supporters of the status quo often have more control over when change initiatives are formally reviewed and voted on, which allows them to ride out pressure for reform by delaying action until issue salience has changed in their favor (Capoccia 2016, 1097). Drawing on these strands of scholarship, we would expect that institutional change attempts are a regular occurrence in the life of institutions and, given the constraints that institutions place on strategic action, many change attempts will fail.

We define failed (change) attempts as events where agents attempt to formally change existing institutions at time $t$ and fail to realize institutional change as a result of this attempt. Failed attempts are a heterogeneous class of events. There can be failed institutional change attempts in electoral system reform, health care policy, legislative politics, and so on. The particularities of a failed attempt will vary across domain or issue area based on the institutional rules for what counts as a formal change attempt, the nature and number of veto points, the context, balance of power, and coalitions involved. Two characteristics of failed formal change attempts are relevant to the subsequent discussion. 
(1) Formality: This paper focuses on formal bids at institutional change by actors who are empowered to initiate or propose a change in the institutional status quo. This includes, for instance, putting a bill, an amendment to a bill, or policy proposal to a vote. Back-room conferrals, behind-the-scenes horse-trading, lobbying, and protests are informal attempts at institutional change. Informal attempts, especially by constituents and stakeholders who hold institutional power, can set the stage for formal institutional change attempts and are important aspects of strategic action around a formal attempt (Helmke and Levitsky 2004; Waylen 2014). Informal attempts are often routine and ongoing which makes them difficult to periodize. Similarly, non-compliance with institutional rules is also different from formal attempts at institutional change even if such non-compliance precipitates formal institutional change (Mahoney and Thelen 2010, 10-1). While informal attempts and non-compliance with rules are important mechanisms of institutional change, we focus on the under-theorized role of failed formal institutional change attempts in institutional development. A failed attempt is an actual, discrete event where actors engage in concrete action. The attempt is identifiable by the time and place of its occurrence and its substantive content. The start of a formal change attempt can be difficult to pinpoint since the initial discussions about institutional alternatives may occur out of the public eye. Yet, it becomes visible to other actors or even the public at large when it reaches a formal decision-making body (Immergut 1992b, 63-4). Depending on the institutional context, formal decision-making bodies can include legislative committees, the parliamentary floor, cabinets, and party conferences. Failed attempts show contenders and supporters aspects of the constraints and opportunities of the current institutional arrangement that might otherwise remain hidden (e.g. Immergut 1992b, Ch. 4). In the remainder of the paper, "failed attempts" refers to failed formal institutional change attempts. 
(2) Failure to cross formal decision points: A formal institutional change attempt fails when it reaches but does not succeed in passing a formal decision point. The decision point could be a vote in a referendum, legislature, or intra-party arena, a bill making it out of committee, or a cabinet decision on a policy proposal. This paper focuses on formal institutional change attempts and hence on decision points that are likewise formal, identifiable and public. The 'failure' occurs when actors empowered to make decisions down-vote a formal change attempt. Policies have been analyzed as institutions (Hacker 2004; Pierson 1993), and there is a vibrant literature in the policy sciences on defining policy failure (Marsh and McConnell 2010; Howlett et al. 2015; McConnell 2015). The paradigmatic case of policy failure is the failure of policy implementation - an existing policy in the process of implementation fails to meet the goals and expectations of its constituents and stakeholders. While policy scholars stress the elusiveness, messiness, and contestability of defining policy failure (McConnell 2015), our focus is not on policy failure as defined above but on institutional change attempts reaching a formal decision point and failing to cross that hurdle. ${ }^{1}$ The failure of a formal institutional change attempt to cross a formal decision point is not contestable or elusive. It is the political and strategic effects of a failed attempt and its implications for the post-failure institutional trajectory that are open to debate and yet to be realized as we will show in this paper. For some actors, the very making of a formal institutional change attempt, even if it fails, connotes a success. For example, the failure of an attempt to legalize abortion in Argentina was deemed successful at creating cultural change. A commentator on the failed legalization said, "the cultural battle is won" (Piñeiro 2018). The commentator did not contest that the attempt at formal institutional change failed - it did not clear the threshold of votes required in the Argentinian senate. Many institutions include several components with distinct sets of rules and regulations, like different parts of a policy or 
electoral system (e.g. electoral formula, electoral tier, district magnitude). Formal change attempts can succeed or fail with regard to some components of such an institution but not others. However, it remains incontestable whether a formal attempt to change a specific rule, clause, or policy component succeeded in crossing a decision point or not. We revisit this point later in the paper.

Our definition of failed institutional change attempts helps to clarify the definitional contours of negative cases. Failed attempts are a conceptually distinct and worthwhile-to-study subset of negative cases. Negative cases are often conceptualized as the non-occurrence of a particular outcome or event (e.g. Mahoney and Goertz 2004). Failed attempts are similar to non-events the outcome does not occur although theoretically relevant triggers for its occurrence are present. Yet, unlike missing transitions or non-events, failed attempts are characterized by actors trying to realize a particular outcome and failing to do so. Failed attempts are not counterfactuals, but an empirical occurrence of an attempt to change an institution. ${ }^{2}$ An illustration is the history of parliamentary reforms in the United Kingdom. In 1822, Whig Lord John Russel introduced a bill to reduce the discrimination against religious minorities and the underrepresentation of more populated parts of the country. His proposal was only backed by around a quarter of MPs and failed to pass (Ertman 2010, 1005-6). Negative cases thus include two subsets: In both subsets, a theoretically possible outcome of interest is absent. What differentiates the two is whether actors have made an attempt to realize this outcome. This paper focuses on the subset of cases where such attempts are made.

Our understanding of failed institutional change attempts extends and refines the concept of “near misses” (Capoccia and Kelemen 2007; Capoccia and Ziblatt 2010). Capoccia and Ziblatt (2010: 943) define near misses as "alternatives [that] were articulated and considered, and at 
times narrowly defeated", "quasi-reform", or "nonselected options of institutional reform". We depart from their work on two grounds: First, failed attempts do not have to be "near" misses. Near misses imply the closeness of the failure to change an institution, like suffrage reforms that failed "by only a very narrow margin" (Capoccia and Ziblatt 2010, 943). They are "close call counterfactuals" (Capoccia and Kelemen 2007, 357), reflecting the contingent nature of critical junctures in this tradition of the literature. In contrast, the margin of defeat does not matter for our definition of failed institutional change attempts. Second, near misses have been seen as events that, in the absence of another critical juncture, make the institutional outcome of interest unlikely to occur in the future, thus making the institutional sequence a negative case (Capoccia and Kelemen 2007, 352; Capoccia and Ziblatt 2010, 941-3). However, many change attempts, if defeated or reversed, still allow proponents to marshal their energies and strategies and make another attempt at a later time. For instance, legislation providing full enfranchisement of women was introduced no less than 47 times between 1945 and 1967 in Switzerland before being accepted at the federal level in 1971 and in all cantons by 1990 (Banaszak 1996, 16, 19). The possibility of causal links between two institutional change attempts must be assessed to determine whether successive change attempts should be treated as independent cases or as events of the same (causal) process (Falleti and Mahoney 2015). The analysis of failed attempts can improve the use of negative cases and near misses in comparative research by encouraging scholars to explain why they expect the outcome not to occur in the future (Büthe 2002, 488).

\section{Analyzing Failed Institutional Change Attempts as Part of Institutional Sequences}

In a first step when analyzing the effect of failed institutional change attempts on an institutional sequence, researchers need to identify such attempts. Failed formal institutional change attempts 
can be identified when a change proposal, such as a bill or policy proposal, reaches a decisionmaking body (e.g. the legislative floor, party committee, or cabinet meeting). When a change proposal fails to cross a decision point in this decision-making body by, for example, being voted down, a failed formal institutional change attempt ends. The granularity of the change attempt can be operationalized in line with the research question. An attempt at legislative change, for example, could be subdivided into introduction and discussion in a committee, move to and discussion in the plenary, and vote and failure in the plenary. Acknowledging that failed change attempts are an empirical regularity in institutional change requires a data collection strategy that aims to uncover such attempts. For example, legislation can have a complex history that can be difficult to track down: the name of the legislation might change over consecutive rounds of voting, it might be voted on by different committees or chambers and previous drafts might be dismantled and reassembled in subsequent attempts. Figure 1 is a schematic periodization of such a narrative of institutional change attempts. A first institutional change attempt $A_{l}$ is observed at time $t_{1}$ and fails to effect institutional change $(\sim \mathrm{Y})$. It is succeeded by a second institutional change attempt, $A_{2}$, observed at $t_{2}$, which also fails to effect change $(\sim \mathrm{Y})$. At time $t_{n}$, an $n^{\text {th }}$ institutional change attempt, $A_{n}$, is made and is successful - the outcome $Y$ is achieved.

\section{FIGURE 1 ABOUT HERE}

In a second analytical step, for every failed attempt, the researcher could assess the attempt for its political effects on the subsequent trajectory of the institution. The researcher can evaluate at least four possible political effects of a failed change attempt. 1) The failed change attempt is a 
blip in the life of the institution, i.e. no effect on the prospects of subsequent change attempts. It seems plausible that minor change proposals, such as amendments or tweaks to close legal loopholes in policy instruments, could fail without building or diluting the groundwork for future attempts. 2) The failed change attempt has negative effects on the prospects of realizing the change proposal, potentially even inoculating against future change attempts. Immergut's (1992a) study of health care reform in Switzerland shows how failed attempts incentivized change agents to dilute their policy proposal in order to attract political support, thus moving away from their initially envisioned outcome. 3) The failed change attempt pushes change agents to change their strategy to realize their preferred outcome by, for example, switching to noncompliance or layering. The last option is in line with gradualist and endogenous theories of institutional change (e.g. Mahoney and Thelen 2010). 4) Finally, the failed change attempt has a positive effect on change agents' prospects of realizing their initial proposal.

This fourth potential effect, where failed change attempts strengthen rather than weaken change agents, has been under-explored in the literature. While actors may fail to introduce formal institutional change, they can affect future negotiations by influencing the ideational basis of the discussed institutional options. Ideas play an important role in structuring political bargaining, and can shape actors' preferences, facilitate collective action, and frame the struggle over existing institutions (Berman 1998; Blyth 2002; Schmidt 2010). Failed attempts can destabilize ideational categories and shake up the coalitional arrangements that coalesce around them. By linking ideas to a specific proposal for institutional change, change agents can provide counterpoints to the accepted ideational basis that has sustained the status quo and that other actors could pick up on in subsequent rounds of institutional change (see Tulis and Mellow 2018: Ch. 2). This could be a new idea or an existing one that has not been considered in the particular 
institutional arena. Once actors have introduced a contending idea into the debate on institutional development, it can gain traction among other actors (Schmidt 2010, 15-6). In this way, failed change attempts can have coalition-building potential, helping actors to discover joint interests (compare Capoccia 2015, 160-1). Failed change attempts can also have political effects if agents agree to concessions. Previous accounts have shown that change agents make concessions by diluting their change proposals (Immergut 1992a). However, concessions can also strengthen change agents. They could receive a concession on an unrelated issue (i.e. a sop) or a concession on the same issue (i.e. slippery slope) (Morrison 2011, 696-8). The concession is an acknowledgment of the change agents' power, while also indicating continuing efforts to prevent or resist change by supporters of the institutional status quo (as they do not capitulate but attempt to placate change agents) (ibid.: 684-5). By agreeing to concessions, supporters of the status quo underscore the legitimacy of institutional change attempts.

The groundwork established through failed attempts can help change agents realize their desired institutional outcome when contextual developments widen the scope for institutional change. In such moments, actors can usually choose between several options. They could let the existing institution drift or replace it with a different institution. When deciding to replace an existing policy, actors are likely to choose an alternative that both explains the inadequacy of the previous policy for an intended purpose and promises to better meet this purpose (Walsh 2006, 494, 4978). The groundwork established through failed change attempts may be highly consequential at this stage. Change attempts can introduce ideas that highlight the flaws of the institutional status quo while offering alternatives. Coalitions emerge around these ideas that change agents can now draw on, and a history of concessions may further back their preferred institutional change. We illustrate such a sequence in Section III through the case of the successful introduction of 
proportional representation after multiple failed attempts in the Italian political party Democrazia Cristiana (DC).

The four potential political effects of failed attempts can be assessed to determine whether an institutional sequence can be classified as a negative case. If the political effect of a failed attempt is best characterized as a blip, it implies that future change attempts might occur but are unpredictable. A blip does not introduce new ideas, does not build or destroy coalitions, and does not yield concessions that support or weaken the cause of change agents. ${ }^{3}$ If the change attempt seems to have resulted in an inoculation, the researcher can be more confident in classifying this sequence as a negative case. Signs of inoculation include the crumbling of the coalition promoting institutional change. A shattering defeat, for example, might disillusion some actors and discourage them to support another attempt. Alternatively, the contenders may have shown their hand too early (Capoccia 2016). Opponents to institutional change might thus be able to discredit poorly thought-out ideas or extract concessions from change agents that significantly alter the latter's proposal. If change attempts link change proposals to ideas that galvanize change agents, help build coalitions, or garner concessions, they may lay the groundwork for future attempts. Finally, if a failed attempt convinces actors to have better chances of realizing their preferred outcome through a different strategy, we would expect them, for example, to switch from displacement to layering, engage in non-compliance, or seek the re-interpretation of existing rules. Section IV illustrates such an analysis of the post-failure trajectory through the analysis of the unsuccessful attempts to legislatively repeal the Affordable Care Act in the U.S. in 2017 .

The prevailing context is likely to shape change agents' incentives to attempt formal institutional change, the format and content of the attempt itself, and their prospects of succeeding with this 
attempt. We explore these questions through the empirical illustrations below. We briefly consider two antecedent factors that might influence change attempts - (in)sincerity of the attempt and the probability of success estimated by change agents. We can assume that actors make change attempts with an estimation of the probability of success. Actors might incorrectly estimate this probability. They might mistakenly assume that their change initiative has a high probability of success due to, for example, an error of judgment about coalitional strength, a poorly thought-out strategy, or legal inconsistencies between the proposed change and the existing institutional arrangements. In many domains, it is costly to make a formal change attempt, so actors are unlikely to make them until they are relatively sure of the outcome. Legislative bills are usually not put to vote until legal counsel has weighed each word, and loopholes that would allow repeal have been patched up. Still, actors sometimes make a formal change attempt even though they anticipate that it might fail because the very making of an attempt at institutional change has political effects beyond its failure to realize a particular institutional outcome. Contenders may make a (non sincere) change attempt that is likely to fail in order to create a basis for subsequent attempts, to garner concessions on other issues, or to appeal to their core constituency. ${ }^{4}$ For instance, between 2010 and 2016, the Republican controlled House made multiple attempts to repeal the Affordable Care Act (ACA) in full or in part. These attempts were symbolic since it was clear that President Obama would veto the bills (Béland, Rocco and Wadden 2018a; 2018b; Hacker and Pierson 2018). These attempts, however, kept discussion over the law's efficacy alive and accompanied less public efforts in courts and at the state level to undermine implementation (Béland, Rocco, and Wadden 2018a, 690). 


\section{Failed Change Attempts and Subsequent Institutional Reform}

A growing literature in comparative politics focuses on institutional development within political parties (e.g. Gauja 2016). Against the backdrop of rising anti-elite sentiments among many voters, parties' transition toward more inclusive rules and procedures to elect party leaders and candidates has attracted scholarly attention (e.g. Cross and Katz 2015). Within the party politics literature, Italy's Christian Democratic Party (DC) is a paradigmatic case of a dominant and factionalized party (Boucek 2012). As Italy's largest governing party for almost half a century, the DC was highly influential in European politics after World War II. The party's decision to introduce a proportional representation system for its internal elections in 1964 proved consequential. It was followed by the escalation of internal factionalism and the party's dependence on bribes to forge internal coalitions and maintain electoral support (Leonardi and Wertman 1989, 114-5; Boucek 2012, 152-82). Both aspects delegitimized Italy's political system and prepared the way for the corruption scandal in the 1990s that led to the DC's collapse.

A sequence of failed attempts preceded the introduction of a proportional representation (PR) system for internal elections in Italy's Christian Democratic Party (DC). The DC initially used a majority system for the election of national party committees. This system was used at internal elections in 1943, 1944, 1945, and 1946. Over these years, however, some leaders of intra-party factions had become dissatisfied with their seat share within the party leadership. This dissatisfaction motivated them to make attempts to change the intra-party electoral system. These factional leaders were members of the party committees that decided on statutory changes (i.e. the national party council and the national party congress). They were empowered to propose a motion at committee meetings, which, if successful, would have led to the adoption of PR within the DC. Their proposals, however, failed to pass a formal decision point at meetings in April and 
September 1946, 1947, 1949, 1954, and 1956 (notated in Figure 2 as $A_{1}$ to A6). Successful institutional change did not take place until the final (seventh) attempt in 1964.

FIGURE 2 ABOUT HERE

The introduction of PR for internal elections in the DC shows how failed attempts can help change agents to achieve their desired outcome in subsequent periods. The failed change attempts laid the ideational groundwork for institutional alternatives, facilitated coalition building, and achieved concessions from the supporters of the institutional status quo. Change agents built on this established groundwork to realize institutional change. Thus, the DC case shows that failed change attempts can be an important part of the events and gradual build-up that often result in institutional transformations.

Introducing Contending Ideas: Proportional representation, and the associated idea that politics should integrate and reflect the preferences of diverse actors, was not new in Italy or the DC. It had influenced the choice of a PR system for Italy's parliamentary elections before and after fascism (Seton-Watson 1967, 547; Smith 1997, 435), and, within the DC, at the subnational level in 1946. ${ }^{5}$ However, the idea of valuing cohesiveness and unity underpinned the use of a majority system to elect the party's national executive committees. The vision of a strong cross-class party with a cohesive leadership dominated the DC's National Council under the leadership of Alcide De Gasperi. This vision resonated with the importance for many Catholics to establish a unified bulwark against a popular Communist Party and the challenges of Italian reconstruction after World War II (Webster 1961, 171, 181; Galli and Facchi 1962, 38; Warner 2000, 109-10). 
This system and De Gasperi's political talent helped him to avoid contested leadership elections and maintain control over the party (Capperucci 2010, 81, 110, 113).

Left-leaning minority groups criticized the majority system for undermining the adequate representation of intra-party diversity in the DC's leadership body. Some left-leaning Christian Democrats from Rome presented PR as an institutional alternative to the majority system. It would allow, they argued, for the better representation of minority groups in the DC's leadership committees and should be used for internal elections. ${ }^{6}$ A majority system prevailed in April 1946 and again provided those supportive of De Gasperi with an absolute majority. ${ }^{7}$ Yet, another leftwing minority group, this time from the Italian north, followed up on the idea of PR as an integrative tool in intra-party politics. They proposed replacing the majority system with a PR and quota system that enhanced the seat share of minority factions. Their proposal was foiled by De Gasperi's majority (Capperucci 2010, 119-21). ${ }^{8}$

Although the first attempts to replace the majority system with a PR system failed, the idea of PR as a tool to ensure respect for internal pluralism and facilitate the integration of different groups within the party leadership had been introduced to the debate on the DC's internal electoral system. Change agents would subsequently pick up on these rhetorical counter-points against the ideational basis that sustained the status quo.

Coalition building: The DC's right-wing faction built on the left's line of reasoning in the run-up to the subsequent national congress in 1947. They emphasized that PR would integrate the pluralism within the DC, help mobilize a range of social and political groups, and increase the DC's chances to defeat the rising Communist and Socialist Party (Capperucci 2010, 139). While their proposal ultimately failed because the DC's left fell in line with the majority's call for party 
unity in the face of the upcoming election (Capperucci 2010, 169-224), ${ }^{9}$ the idea to introduce PR had started to be acceptable to diverse groups and thereby gain legitimacy.

When the DC's right-wing faction endorsed the idea of PR as an organizing principle for intraparty politics, it revealed the coalition-building potential of failed institutional change attempts. The DC's right- and left-wing factions were usually opposed to each other since they held quite different views on, for instance, economic policies and the coalition formula for government formation (Boucek 2012, 145-7). Yet, as minority factions, they started to see their joint benefit from PR. Demands for introducing PR thus started to generate bi-partisan support within the DC. The first pro-PR coalition brought together Dossetti's left-wing faction, Giovanni Gronchi's trade unionist faction, and Domenico Ravaioli's group. Even though their attempt to get PR on the agenda for the 1949 party congress was foiled by the majority faction (Capperucci 2010, 30810), the coalition contributed to the consolidation of PR rather than a quota system as the predominant alternative to the existing majority system. ${ }^{10}$

The four failed attempts to realize PR within the DC between 1946 and 1949 had yielded concrete political effects: They had helped to undermine the ideational appeal of values such as party unity and respect for hierarchies by juxtaposing them to the benefit of pluralism, mediation, and integration. Around this dichotomy, coalitions emerged which went beyond the initial factional boundaries within the party by revealing shared interests between traditionally opposed groups.

Gaining Concessions: Following minority factions' attempts to replace the DC's majority with a PR system, De Gasperi wanted to encourage small factions to join his majority group. For the subsequent national congress, he proposed that the plurality slate would gain four-fifths of the party council seats, while the remaining one-fifths were split among the minority candidates. 
This proposal was a concession toward minority factions on two grounds: For the first time, it formally reserved a share of party council seats elected by the national congress for minority factions, thus acknowledging minority factions' demands for representation. ${ }^{11}$ Moreover, De Gasperi's proposal only passed after he had given the different factions virtually proportional representation on his own candidate slate for the party council. ${ }^{12}$ Against De Gasperi's intentions, however, this adjustment encouraged party elites to strengthen their factional ties. A faction only needed to win a narrow plurality at the national congress to gain a substantial seat share at the party council, which increased small factions' role as pivotal coalition players in the formation of the plurality slate (Boucek 2012, 147-9). The concession also fueled competition between minority factions over the seat share reserved for the minority (Leonardi and Wertman 1989, 111).

Having reached the first concession on the contested issue, minority factions continued their efforts to introduce PR. A cross-factional coalition, ranging from the party's left to center-right, narrowly lost the vote on their motion in favor of PR at the 1954 party congress (Capperucci 2010, 632-42). ${ }^{13}$ When pressure for introducing PR remerged in the run-up to the next national congress, the DC's majority faction agreed to increase minority factions' seat share on the party council from one-fifth to one-third. ${ }^{14}$ This helped to appease some minority factions and thereby to split the pro-PR coalition. While the national congress voted against introducing PR, ${ }^{15}$ minority factions had received the second concession that acknowledged the legitimacy of their call for better representation.

Capitalizing on the Established Groundwork: The majority system that had remained in place after the concessions in 1952 and 1956 was increasingly seen as one of the reasons for the escalating factionalism within the party and the high level of parliamentary and governmental 
instability. As Guido Gonella had already put it in July 1956: "The majority system ...

aggravates the divisions into organized groups which end up fighting outside the party because it deprives minority groups of the chance to express themselves directly within party committees." ${ }^{\prime 16}$

Analyzing previous sequence of failed attempts helps understand why the Christian Democrats decided to introduce a PR system. The DC could have let the institution drift, shifting toward a more informal approach to integrating the different factions, as De Gasperi had done in 1952. They could have introduced a quota system to guarantee the representation of different groups, an alternative that was discussed in 1946 but gradually disappeared from the debate as minority factions coalesced around PR (Capperucci 2010, 119-21). While it could be argued that institutional change was straightforward because PR was the only option on the table once the majority system had been discredited, this view does not appreciate the effects of actors' repeated attempts to introduce PR for almost 20 years. The debate over electoral systems became a debate between PR and a majority system, and coalesced around the former's merits and the latter's flaws. The way minority factions had framed PR in their failed attempts to introduce it in the past (i.e. as a method of integration) made it gradually appear as a way of coping with the party's factionalism. ${ }^{17}$ Concessions had further legitimized minority factions' demands for integration, and as PR had generated support from both right- and left-wing factions, it was not seen as partisan. After another intra-party crisis over the government's coalitional format, one of the factions resigned from the party leadership, depriving party leader Aldo Moro of his narrow majority (Boucek 2012, 151-2). In their resignation letter, the members of this faction advocated adopting PR to weigh each opinion within the party by its level of support. ${ }^{18} \mathrm{PR}$ gained widespread support because it seemed to allow for a better translation of factions' strength into 
seats on the party leadership and, consequently, a lower likelihood of intra-party conflict and defection in parliament. ${ }^{19}$ It was passed in January $1964 .^{20}$ This happened after the DC's leadership had split and re-arranged several times before the reform of 1964 (Boucek 2012, 14752), underlining that the introduction of PR cannot be explained by changes in who was holding power.

Would the Christian Democrats have introduced PR even without previous failed attempts? Institutions can be changed in a top-down manner, for example, through charismatic reformers particularly during critical junctures, crisis moments, or policy windows. However, the rise of such charismatic reformers is unlikely in highly factionalized parties like the DC (compare Krauss and Pekkanen 2015, Ch. 8). By taking failed change attempts seriously in the DC case, we can see that factional conflicts were not merely an antecedent for the introduction of PR. Failed attempts to introduce PR increased factionalization, for example, through obtaining concessions that increased small factions' importance as pivotal coalition players and fueled competition between minority factions. Failed attempts were also associated with new ideas and the building of bi-partisan coalitions within the DC. Failed attempts thus played an important role in the process through which institutional change was ultimately achieved.

\section{Assessing Alternative Effects of Failed Institutional Change Attempts on the Post- Failure Trajectory}

An emergent literature analyses the origins and transformation of arguably one of the most significant changes in US social policy in recent years, the Patient Protection and Affordable Care Act (ACA) (Oberlander and Weaver 2015; Béland et al. 2018a; 2018b; 2020; Hacker and 
Pierson 2018). The ACA was passed in 2010 by the Obama administration in a very partisan climate, with no Republicans voting for the bill (Reynolds and Hall 2018). It is a complicated policy with many moving parts designed to affect the behavior of consumers, insurers, state agencies, and medical providers. There have been many attempts by Republicans to change this policy starting immediately after it was enacted into law. These attempts include legislative attempts at repealing the law in whole or part, legal challenges by states, executive actions, public protests, and non-compliance or non-implementation (Oberlander and Weaver 2015; Béland et al. 2018a; 2018b; 2020; Hacker and Pierson 2018). Successive legislative attempts to repeal the ACA in July 2017 failed to introduce new ideas or build coalitions. This section analyzes these failed attempts to evaluate the different effects failed institutional change attempts can have on the subsequent institutional trajectory.

For analyzing the attempts to repeal the ACA, we focus on bills to repeal the ACA that came to a vote. Four such change attempts can be identified in 2017: 1) the successful passage of the House AHCA (American Health Care Act, May 2017, 217-213), which the Senate declined to take up, and three failed Senate Bills, 2) a repeal and replace legislation, the BCRA (Better Care Reconciliation Act, 43-57), 3) a repeal-only legislation, which was a revamp of a 2015 bill that had passed both houses of Congress but was vetoed by Obama (Obamacare Repeal and Reconciliation Act of 2017, 45-55), and 4) the so-called 'Skinny' repeal (Health Care Freedom Act 2017, 49-51) (Thompson et al. 2018; Béland et al. 2020). The three Senate bills were proposed and voted on in a very short period of time - July $25^{\text {th }}$ to $28^{\text {th }}$, with overlapping debates. Whether a legislation should be classified as a repeal of the ACA is not always clearcut. By a strong definition, skinny repeal would not qualify since it aimed at a limited set of ACA components. Skinny repeal included zeroing out the individual and employer mandates, 
and allowing states greater latitude in obtaining waivers from ACA regulations. ${ }^{21}$ Since skinny repeal was interpreted at the time as the end of the road for significant reform, we include it as a failed attempt at repeal. Although the previous attempts had kept the debates and revisions going, the failed attempt of skinny repeal had a 'ring of finality' with McCain's dramatic thumbs-down gesture (Pear and Kaplan 2017). In the following discussion, we will focus on the political effects of Skinny repeal on the subsequent trajectory of the ACA.

In evaluating the political effects of a failed institutional change attempt on the subsequent sequence of events, four alternative explanations can be considered (see Section II). The first is to assess whether the failed attempt is a blip in the institutional trajectory and has little effect on the probability of future successful change (i.e. null hypothesis). Attempts to repeal the ACA were not blips. For example, the failure of Skinny repeal was a significant, much-publicized political event (McCain's thumbs-down has entered political history) that involved intense lobbying and political bargaining.

Second, it is possible that failed attempts lay the groundwork for future attempts by introducing alternative ideas, building coalitions, or garnering concessions (see Section III). The repeal and replace attempts by the Republicans failed to introduce a comprehensive alternative to the ACA. Since the ACA drew on conservative health-care ideas, including the Massachusetts model, repeal attempts failed to propose new conservative ideas as counterpoints to the status quo (Oberlander and Weaver 2015; Béland et al. 2018a). Successive repeal attempts also failed to build new coalitions, for example, across the partisan aisle or with associations of experts (such as the American Medical Association or the American Association of Retired Persons) (Béland et al. 2018b). ${ }^{22}$ Rather, the successive repeal attempts in 2017 highlighted the lack of agreement among the Republicans on an alternative to the ACA. 
Third, it is possible that a failed attempt kills the contending movement and inoculates the institution against future attempts of this type. There is some evidence of inoculation as a result of the failed legislative repeal attempts - apparent in the three hectic days of July $25^{\text {th }}-28^{\text {th }}$ of 2017. The attempts to repeal the ACA weakened over these three days - from repeal and replace, to repeal only, to skinny repeal (all voted down). The failure of these repeal attempts in rapid succession signaled a crushing defeat for the Republican Senate majority leader. It shows that failed attempts can be attended by learning effects. After the failure of skinny repeal, Senate majority leader Mitch McConnell changed his estimate of the probability of legislative repeal, and concluded that it was "time to move on". He scrapped further votes, and called for bipartisan solutions (Berman 2017). The failed attempts exposed the lack of comprehensive alternative Republican policies to repeal and replace the ACA. They also highlighted the factionalization within the Republican Party on healthcare reform, with some conservatives leaning away from repeal and others leaning toward even more drastic changes such as block-granting Medicaid (Béland et al. 2018a; Hacker and Pierson 2018). Attempts to weaken the ACA have continued after the failure of skinny repeal (executive actions, legal challenges, zeroing out the penalty of the individual mandate, and judicial decisions including a late 2018 ruling in Texas that declared the ACA unconstitutional as a consequence of the removal of the individual mandate). Legislative repeal of the ACA, however, has become less likely.

The failure of successively weaker repeal attempts (repeal and replace, to repeal only, to skinny repeal), the air of finality around the defeat of skinny repeal, and the last-ditch Graham-Cassidy bill not being moved to a vote pushed Republicans away from legislative repeal of the ACA. The repeal efforts resulted in public opposition, including through heated town hall meetings with Republican representatives who supported repeal legislation (Zernike 2017), and arguably helped 
the Democrats win the House in 2018. The Democrats' win of the House changed the number of veto points for legislative repeal. Public opinion toward the ACA has also remained mildly favorable (Kaiser Family Foundation 2019). In the run-up to the 2020 elections and in the context of a global pandemic, the overall ideational regime around healthcare has moved left (universal coverage, Medicare for all, single-payer; see Béland et al. 2018a).

Finally, change agents could respond to failed attempts by changing strategies, pursuing piecemeal change, re-interpreting the rules, or engaging in non-compliance in order to achieve their desired institutional outcomes (Helmke and Levitsky 2004: 729-30). This appears to be the case with the ACA (Béland et al. 2020). Following the failure to get their health care bills passed, Republicans changed their legislative repeal strategy by switching issue domain. For doing so, they built on the Supreme Court's decision in NFIB vs. Sebelius (2012), which had upheld the constitutionality of the ACA on the grounds that the individual mandate was a tax. This allowed Republicans to eliminate the penalty imposed by the individual mandate, the most unpopular part of the ACA, by adding it to the Tax Cuts and Jobs Act of 2017. Introducing a $\$ 1.5$ trillion tax cut, the bill gained broad Republican support and was signed into law in December 2017 (Jacobs 2017). The Tax Cut and Jobs Act did not repeal the individual mandate but zeroed out the penalty, thereby making the mandate 'hortatory' (Gais and Gusmano 2020). Zeroing out the penalty does not amount to repeal of the ACA. Indeed, a number of developments after that indicate that the ACA, or at least many of its policy instruments, remain resilient (Gais and Gusmano 2020; Béland et al. 2020). However, zeroing out the penalty has effectively changed parts of the ACA. It complements executive decisions taken to undermine implementation and destabilize the program. For example, reductions in advertising budget and outreach, shortening the sign-up period, introducing less comprehensive health plans through 
executive action, all of which add up to 'death by a thousand cuts' (Béland et al. 2018a: 693).

This non-compliance strategy is likely to be better at accommodating the Republican state-level divide around the ACA.

Our discussion above suggests that legislative repeal is unlikely in the current context. The public health crisis as a result of the Covid-19 pandemic might expose new rifts in the health safety net. The pandemic is a true exogenous event, and the past balance of power, coalitions, and institutional context have rapidly changed. This period could open new policy windows that change agents can seize. Yet, the shift toward pushing for change in non-legislative arenas through executive and judicial actions and the Republican strategy to undermine the ACA's implementation at the state level suggests a trajectory of the ACA that continues to be characterized by non-compliance and drift. Such strategies, as theories of endogenous institutional change remind us, allow change agents to gradually pave the way toward shifting the institutional status quo even when facing obstacles to formal institutional change (Hacker 2004; Mahoney and Thelen 2010). As outlined above, failed repeal attempts were associated with this shift of change agents' energy to other arenas (the judicial) and toward gradual change strategies.

\section{Conclusion}

The focus of this paper on failed institutional change attempts follows from the theoretical tension inherent in the study of political institutions. If institutions are the object of frequent "strategic action aimed at various forms of change," while displaying a remarkable level of 
stability, many institutional change attempts will fail (Capoccia 2016, 1115). The politics between supporters and opponents of institutional change underlines the paper's central argument to give moments of failed institutional change attempts a more explicit role in analyses of institutional development.

Studying the effects of these important events on the trajectory of institutions entails concrete benefits. Many elements associated with gradual change (new ideas, changing coalitions, concessions in related or different areas) emerge from failed attempts. The first failed attempt can introduce new or contending ideas about institutional alternatives. Subsequent attempts send a signal that the opponents are not giving up on effecting institutional change. Over time, institutional alternatives become more acceptable, and coalitions start to coalesce around them. Opponents of institutional change might be forced to grant concessions that further cement the contending ideas and coalitions, thereby making successful change more likely. Alternatively, an unsuccessful attempt by actors to move the institutional status quo in a specific direction may close off this option for future attempts and incentivize actors to seek institutional change through different means, like drift or non-compliance.

Studying failed institutional change attempts helps improve our understanding of periodization and processes in institutional trajectories. Theorizing the role of failed change attempts might push back the starting point of a causal process by revealing the importance of a failed change attempt in producing the outcome of interest. It might reveal important events in the chain of events that characterizes the development of an institution and specify the effects that shape its post-failure trajectory. By studying a sequence of failed institutional change attempts, our paper makes suggestions for a data collection and analytical strategy that takes this reasoning into account. 
Assessing the political effects of failed institutional change attempts can also improve the selection of negative cases in comparative research by encouraging scholars to explain why they expect the outcome not to occur in the future. Our research underlines that independence between events that are part of the same institutional trajectory cannot be assumed. Instead, the link between any two subsequent change attempts needs to be assessed when researchers choose their cases.

Finally, the value of assessing the political effects of failed change attempts on subsequent institutional development speaks to research on institutional selection. The direction of institutional change is often not inevitable since decision-makers can usually choose among several options. As decision-makers' time and resources are limited, the ideas, coalitions, and concessions introduced through failed change attempts can tip the scales in favor of a previously unsuccessfully promoted institutional alternative.

Actors' unsuccessful attempts to realize change should be given as prominent a place in the study of institutions as moments of successful institutional modifications. Future research would benefit from analyzing failed change attempts for what they are: potential key drivers of institutional development. 
${ }^{1}$ This would be termed an "outright process failure" in the policy literature.

${ }^{2}$ We are indebted to an anonymous reviewer for this point.

${ }^{3}$ Defining such 'minor' attempts requires domain- or case-specific information.

${ }^{4}$ We are grateful to an anonymous reviewer for this point.

${ }^{5}$ La Convocazione del Congresso Nazionale, 20.01.1946, p. 2, ADG-77, HAEU. Archival material is from the Fondo Alcide De Gasperi (ADG), at the Historical Archives of the EU (HAEU), Florence, and the Fondo Democrazia Cristiana at the Archivio Storico, Istituto Luigi Sturzo (Asils), Rome. Translations by author.

${ }^{6}$ HAEU, Il progretto di statuto e le mozioni presentate da 'Tendenza' e 'Politica d'oggi', p. 3, 11, ADG-78.

${ }^{7}$ Data: Consiglio Nazionale della D.C. 29.04.1946, in Salvi (1959: 217-8).

${ }^{8}$ Consiglio Nazionale. 18.-22.09.1946, in Salvi (1959: 239).

${ }^{9}$ The DC's left had not abandoned their preference for PR. The fear of a Socialist-Communist victory in the looming election convinced them to comply with De Gasperi. See Dossetti, "Fisionomia del II Congresso della DC," 30.11.1947, Cronache Sociali, in Trotta (1995: 184, 187).

${ }^{10}$ Asils, Seduta Antimeridiana, 27.04.1949, pp. 6-10; Seduta Pomeridiana, 27.04.1949, p. 1;

Seduta Pomeridiana, 28.04.1949, p. 7, Consiglio Nazionale, Sc. 5 Fasc. 14.

${ }^{11}$ Asils, “I Nuovi Dirigenti della D.C.," Il Tempo, 27.11.1952, Congresso Nazionale, Sc. 4.

${ }^{12}$ See the letters and De Gasperi's various drafts of his slate in HAEU, ADG-78.

${ }^{13}$ Asils, Proposta di Modifica dello Statuto; Seduta Notturna, 28.06.1954, pp. 3-5; Seduta

Antimeridiana, 29.06.1954, p. 1, Congresso Nazionale, Sc. 5 Fasc. 6.

${ }^{14}$ Consiglio Nazionale, 23.07.1956, in Democrazia Cristiana (1957: 7-9, 12-22, 28-30, 35). 
${ }^{15}$ Asils, Seduta Pomeridiana, 15.10.1956; Seduta Antimeridiana, 16.10.1956, p. 1/1, Congresso Nazionale, Sc. 6, Fasc. 7.

${ }^{16}$ Interventi, 23.07.1956, in Democrazia Cristiana (1957: 15).

${ }^{17}$ Ibid., 16, 21-22.

${ }^{18}$ Asils, Letter to Moro, 21.01.1964, Direzione Nazionale, Sc. 36 Fasc. 450.

${ }^{19}$ Asils, Verbale, 24.01.1964, pp. 10-12; 25.01.1964, pp. 104-107, Consiglio Nazionale, Sc. 51 Fasc. 73.

${ }^{20}$ Asils, Verbale, 27.01.1964, pp. 367-369, Consiglio Nazionale, Sc. 51 Fasc. 73.

${ }^{22}$ There were attempts to enrol dissenting Republicans, and some coalition-building and concession-granting between successive change attempts. These coalition-building efforts only diluted the change attempts (ending with 'skinny' repeal). 


\section{References}

Banaszak, Lee Ann. 1996. Why Movements Succeed or Fail. Opportunity, Culture, and the Struggle for Woman Suffrage. Princeton, NJ: Princeton University Press.

Béland, Daniel, Philip Rocco, and Alex Waddan. 2018a. "Obamacare in the Trump Era: Where Are We Now, and Where Are We Going?” The Political Quarterly 89 (4): 687-94.

Béland, Daniel, Philip Rocco, and Alex Waddan. 2018b. "Policy Feedback and the Politics of the Affordable Care Act." Policy Studies Journal 47 (2): 395-422.

Béland, Daniel, Michael Howlett, Philip Rocco, and Alex Waddan. 2020. "Designing Policy Resilience: Lessons from the Affordable Care Act.” Policy Sciences https://doi.org/10.1007/s11077-019-09368-w.

Berman, Russell. 2017. “John McCain's 'No' Vote Sinks Republicans' 'Skinny Repeal' Plan”, The Atlantic, July 28.

Berman, Sherry. 1998. The Social Democratic Moment. Ideas and Politics in the Making of Interwar Europe. Cambridge, Mass.: Harvard University Press.

Bernhard, Michael. 2015. "Chronic Instability and the Limits of Path Dependence." Perspectives on Politics 13 (4): 976-991.

Blyth, Mark. 2002. Great Transformations: Economic Ideas and Institutional Change in the Twentieth Century. New York, N.Y.: Cambridge University Press.

Boucek, Françoise. 2012. Factional Politics: How Dominant Parties Implode or Stabilize, London: MacMillan. 
Büthe, Tim. 2002. "Taking Temporality Seriously. Modeling History and the Use of Narratives as Evidence." American Political Science Review 96 (3): 481-493.

Capoccia, Giovanni. 2015. "Critical junctures and institutional change." In Advances in Comparative Historical Analysis, edited by James Mahoney and Kathleen Thelen, 147-179.

New York, NY: Cambridge University Press.

Capoccia, Giovanni. 2016. "When do institutions 'bite'? Historical institutionalism and the politics of institutional change." Comparative Political Studies 49 (8): 1095-1127.

Capoccia, Giovanni, and R. Daniel Kelemen. 2007. "The study of critical junctures: Theory, narrative, and counterfactuals in historical institutionalism." World Politics 59 (3): 341—369.

Capoccia, Giovanni, and Daniel Ziblatt. 2010. "The historical turn in democratization studies. A new research agenda for Europe and beyond." Comparative Political Studies 43 (8-9): 931968.

Capperucci, Vera. 2010. Il Partito dei Cattolici: Dall'Italia Degasperiana alle Correnti Democristiane. Rome, Italy: Rubbettino.

Cross, William P., and Richard S. Katz. 2015. The Challenges of Intra-party Democracy. New York, NY: Oxford University Press.

Democrazia Cristiana. 1957. Consiglio Nazionale D.C. del 23 Luglio 1956. Rome: Edizione 5 luna.

Ertman, Thomas. 2010. "The Great Reform Act of 1832 and British democratization.” Comparative Political Studies 43 (8/9): 1000-1022. 
Falleti, Tulia, and James Mahoney. 2015. "The comparative sequential method." In Advances in Comparative-Historical Analysis, edited by James Mahoney and Kathleen Thelen, 211-239. Cambridge, Mass.: Cambridge University Press.

Galli, Giorgio, and Paolo Facchi. 1962. La Sinistra Democristiana. Storia e Ideologia. Milan, Italy: Feltrinelli.

Gingrich, Jane. 2015. "Varying costs to change? Institutional change in the public sector." Governance 28(1): 41-60.

Goodnough, Abby, and Robert Pear. 2018. “Texas Judge Strikes Down Obama’s Affordable Care Act as Unconstitutional." The New York Times, December 14, 2018.

Gais, Thomas L., and Michael K. Gusmano. 2020. "Putting The Pieces Together Again: American States and the End of the ACA's Shared Responsibility Payment." Journal of Health Politics, Policy and Law 45 (3): 439-454.

Hacker, Jacob S. 2004. "Privatizing risk without privatizing the welfare state: The Hidden Politics of Social Policy Retrenchment in the United States." The American Political Science Review 98 (2): 243-260.

Hacker, Jacob S., and Paul Pierson. 2018. "The dog that almost barked: What the ACA repeal fight says about the resilience of the American Welfare State." Journal of Health, Politics, Policy and Law 43 (4): 551-577.

Helmke, Gretchen, and Steven Levitsky. 2004. "Informal institutions and comparative politics: A research agenda." Perspectives on Politics 2 (4): 725-740. 
Howlett, Michael, M. Ramesh, and Xun Wu. 2015. "Understanding the persistence of policy failures: The role of politics, governance and uncertainty." Public Policy and Administration 30 (3/4): 209-220.

Hunter, Wendy. 2010. The Transformation of the Workers' Party in Brazil, 1989-2009. New York: Cambridge UP.

Immergut, Ellen M. 1992a. Health Politics: Interests and Institutions in Western Europe. New York, NY: Cambridge University Press.

Immergut, Ellen M. 1992b. "The rules of the game.” In Structuring Politics: Historical Institutionalism in Comparative Analysis, edited by Sven Steinmo, Kathleen Thelen, and Frank Longstreth. New York, NY: Cambridge University Press. 57—89.

Jacobs, Ben. 2017. "Republicans celebrate with Trump after House passes tax bill - again.” The Guardian, December 20, 2017. https://www.theguardian.com/us-news/2017/dec/20/republicansplan-celebration-with-trump-after-house-passes-tax-bill-again.

Kaiser Family Foundation. 2019. "The public's views on the ACA." https://www.kff.org/interactive/kff-health-tracking-poll-the-publics-views-on-the$\underline{\text { aca/\#? } \text { response=Favorable--Unfavorable\&aRange=all } .}$.

Krauss, Ellis S., and Robert J. Pekkanen. 2011. The Rise and Fall of Japan's LDP. Political Party Organizations as Historical Institutions. Ithaca, NY: Cornell University Press.

Leonardi, Robert, and Douglas A. Wertman. 1989. Italian Christian Democracy. The Politics of Dominance. London, UK: MacMillan. 
Mahoney, James. 2000. "Path Dependence in Historical Sociology." Theory and Society 29 (4): $507-548$.

Mahoney, James, and Gary Goertz. 2004. "The possibility principle: Choosing negative cases in comparative research.” The American Political Science Review 98 (4): 653-69.

Mahoney, James, and Kathleen Thelen. 2010. "A theory of gradual institutional change.” In Explaining Institutional Change, edited by James Mahoney and Kathleen Thelen, 1-37. New York, NY: Cambridge University Press.

Marsh, David, and Allan McConnell. 2010. "Towards a framework for establishing policy success." Public Administration 88 (2): 564-583.

McConnell, Allan. 2015. "What is policy failure? A primer to help navigate the maze." Public Policy and Administration 30(3/4): 221-242.

Morrison, Bruce. 2011. “Channeling the 'restless spirit of innovation': Elite concessions and institutional change in the British Reform Act of 1832." World Politics 63(4): 678-710.

Oberlander, Jonathan, and R. Kent Weaver. 2015. "Unraveling from within? The Affordable Care Act and self-undermining policy feedbacks." The Forum 13 (1): 37-62.

Payton, Matt. 2016. "Nigerian senate votes down gender equality bill due to 'religious beliefs'." The Independent, March 17, 2016. https://www.independent.co.uk/news/world/africa/nigeriansenate-votes-down-gender-equality-bill-due-to-religious-beliefs-a6936021.html.

Pear, Robert, and Thomas Kaplan. 2017. "Senate Rejects Slimmed-Down Obamacare Repeal as McCain Votes No.” New York Times, July 27, 2017. 
Pierson, Paul. 1993. "When effect becomes cause. Policy feedback and Political Change.” World Politics 45 (4): 595-628.

Pierson, Paul. 2000. "Increasing returns, path dependence, and the study of politics." The American Political Science Review 94 (2): 251-267.

Piñeiro, Claudia. 2018. “Argentina's women have not been beaten on abortion: Change will come." The Guardian, August 10, 2018.

https://www.theguardian.com/commentisfree/2018/aug/10/argentina-women-abortion-hollowsenate-victory.

Reed, Steven R., and Michael F. Thies. 2003. "The causes of electoral reform in Japan.” In Mixed-Member Electoral Systems: The Best of Both Worlds, edited by Matthew Soberg Shugart and Martin P. Wattenberg, 153-173. Oxford, UK: Oxford University Press.

Reynolds, Molly E., and Richard L. Hall. 2018. "Issue Advertising and Legislative Voting on the Affordable Care Act.” Political Research Quarterly 71 (1): 102 - 114.

Salvi, Franco. 1959. Atti e Documenti della Democrazia Cristiana: 1943-1959. Rome, Italy: Cinque Lune.

Seton-Watson, Christopher. 1967. Italy: From Liberalism to Fascism. New York, NY: Methuen.

Schmidt, Vivien. 2010. "Taking ideas and discourse seriously: Explaining change through discursive institutionalism as the fourth 'new institutionalism'." European Political Science Review 2 (1): 1-25.

Smith, Denis M. 1997. Modern Italy: A Political History. New Haven, CT: Yale University Press. 
Streeck, Wolfgang, and Kathleen Thelen. 2005. "Introduction: Institutional change in advanced political economies." In Beyond Continuity: Institutional Change in Advanced Political Economies, edited by Wolfgang Streeck and Kathleen Thelen, 1-39. Oxford, UK: Oxford University Press.

Thompson, Frank J., Michael K. Gusmano, and Shugo Shinohara. 2018. “Trump and the Affordable Care Act: Congressional Repeal Efforts, Executive Federalism, and Program Durability." Publius: The Journal of Federalism 48 (3): 396-424.

Trotta, Giuseppe. 1959. Giuseppe Dossetti. Scritti Politici 1943-1951. Geneva, Switzerland: Marietti.

Tulis, Jeffrey K., and Nicole Mellow. 2018. Legacies of Losing in American Politics. Chicago, IL: Chicago University Press.

Walsh, James I. 2006. "Policy failure and policy change: British security policy after the cold war." Comparative Political Studies 39 (4): 490-518.

Warner, Carolyn M. 2000. Confessions of an Interest Group: The Catholic Church and Political Parties in Europe. Princeton, NJ: Princeton University Press.

Waylen, Georgina. 2014. "Informal Institutions, Institutional Change, and Gender Equality.” Political Research Quarterly 67 (1): 212-223.

Webster, Richard A. 1961. Christian Democracy in Italy: 1860-1960. London, UK: Hollis and Carter.

Zebley, Julia. 2011. “Uruguay fails to overturn 1986 Amnesty Law”, Jurist, May 20, 2011. https://www.jurist.org/news/2011/05/uruguay-fails-to-overturn-1986-amnesty-law/. 
Zernike, Kate. 2017. “They Voted to Repeal Obamacare. Now They Are a Target.” New York

Times, May 8, 2017.

Ziblatt, Daniel. 2017. Conservative Parties and the Birth of Democracy. Cambridge: Cambridge University Press. 
Sukriti Issar is an Assistant Professor in Sciences Po, OSC (Observatoire Sociologique du Changement), CNRS, Paris. Her research interests focus on urban and housing policy, institutional change, and social history.

Matthias Dilling is a Departmental Lecturer in Comparative Politics at Oxford University. His research is on institutional development, party politics, and comparative-historical analysis. 
$\mathrm{t}_{1}$

$\mathrm{A}_{1} / \sim \mathrm{Y}$

$\mathrm{A}_{2} / \sim \mathrm{Y}$

$\mathrm{A}_{\mathrm{n}} / \mathrm{Y}$

A: failed attempt; Y: unsuccessful outcome; Y: successful outcome

Figure 1. Failed attempts in institutional change sequences 


\begin{tabular}{|cccccccc|}
\hline \hline 1943 & 1946 & 1947 & 1949 & 1954 & 1956 & 1964 \\
\hline & $A_{1} A_{2}$ & $A_{3}$ & $A_{4}$ & $A_{5}$ & $A_{6}$ & PR \\
& & & & & & \\
\hline
\end{tabular}

Figure 2. The path toward PR within Italian Christian Democracy 